\title{
Global Governance in the Interregnum ${ }^{1}$
}

\author{
Tom Pegram \\ Lecturer in Global Governance \\ University College, London \\ t.pegram@ucl.ac.uk
}

\author{
Michele Acuto \\ Senior Lecturer in Global Networks and \\ Diplomacy \\ University College, London \\ m.acuto@ucl.ac.uk
}

This is a post-refereed, accepted version. Published in: Millennium, vol. 43(2), January

2015

\section{Introduction}

Global governance is in flux. Scholarship on the practice of global governance has reimagined it as a realm of disputes and confrontation, rather than one of interestalignment within multilateral interstate forums. Old certainties of a new liberal order borne along by the rising tide of globalisation no longer hold. ${ }^{2}$ The global multilateral landscape is generally portrayed as unravelling in the face of proliferating threats. The 69th session of the General Assembly opened with a warning from the UN Secretary General Ban Ki-moon to assembled diplomats that the world is "living in an era of unprecedented levels of crises". 3 Few would disagree that the multilateral order has been found severely wanting in its response to the Ebola pandemic, the rising death toll and international deadlock in Ukraine, and spiralling conflagration in Syria and the surrounding region.

A profound sense of governance deficit is provoking critical reflection both within the corridors of power and among practitioners and scholars. Whether this amounts to a revival of interest in global governance is debatable; after all, the term is rarely invoked in political discussion. For politicians, global governance remains a realm of realpolitik, institutions and membership. The general response to multilateral failure by Western governments has been a retreat into bilateralism, club diplomacy, and 'coalitions of the willing'. Equally, a call within academic circles for renewed reflection on global

\footnotetext{
${ }^{1}$ For extremely useful comments the editors and forum contributors thank Antoine Bousquet, David Chandler, Scott Hamilton, Andrew Hurrell, Lee Jones, Anthony Langlois, Beverley Loke, Michael Mason, Avia Pasternak, Joana Setzer, Nick Srnicek, David Williams, and all the participants at the workshop Global Governance and the Theoretical Interregnum, held at University College London, Institute of Global Governance, London on 23 September 2014. The editors also wish to thank the Millennium editorial team and anonymous reviewers, and, in particular, Cora Lacatus for her guidance and thoughtful commentaries throughout. All errors remain ours alone.

2 See, for example, Anastasia Nesvetailova and Ronen Palan, 'The End of Liberal Finance? The Changing Paradigm of Global Financial Governance', Millennium 38, no. 3 (2010): 797-825.

3 Julian Borger, Ban Ki-moon: 'World living in an era of unprecedented level of crises', The Guardian, 21 September 2014.
} 
governance as a practice-oriented scholarship has elicited varied responses from the international relation (IR) fraternity. In taking stock of the state of the art of 'global governance theory', a number of scholars have advocated for its revival to be grounded in the kind of critical reflection often absent from mainstream IR discussion. ${ }^{4}$ Others contest any meaningful demarcation between IR and global governance scholarship. ${ }^{5}$ Some scholars now even press for its wholesale rejection as an idea whose time has come and gone. $^{6}$

Yet global governance as a theme has not gone away. The reconceptualisation of IR as 'governance without government' by James Rosenau in 1990 continues to animate much discussion on the phenomena of globalisation and the purposive turn towards global governance. ${ }^{7}$ More than twenty years later, the term remains, although the terms of the debate are far from settled. ${ }^{8}$ Attention to what we might consider as 'global governance scholarship' (if not practice) surfaced most prominently in the 1990s as a powerful expression of its context, capturing the inexorable advance of (neo)liberal globalisation and a new world order ushered in by the end of the Cold War. The roots of global governance scholarship are well-embedded in the traditions of IR. In particular, the disciplinary turn in the late 20th century to regime theory and attempts to assess international politics at the macro level cast a long shadow over the current terms of the global governance debate. ${ }^{9}$

This first generation of international systems research has produced significant insights into scope conditions for efficiency gains via enhanced coordination, functional differentiation and the potential for effective regime management through international organisations. ${ }^{10}$ However, scant attention has been given to normative issues of power symmetries, value and norm conflict, or to dominant concerns for interest capture. This omission has impacted upon our ability to explain how global governance structures actually work in practice, and why and when they matter, also limiting our ability to

\footnotetext{
${ }^{4}$ Thomas G. Weiss and Rorden Wilkinson, 'Rethinking Global Governance? Complexity, Authority, Power, Change', International Studies Quarterly 58, no. 1 (2014): 207-215; John Ruggie, 'Global Governance and "New Governance Theory": Lessons from Business and Human Rights', Global Governance 20, no. 1 (2014): 5-17.

${ }^{5}$ Martha Finnemore, 'Dynamics of Global Governance: Building on What We Know', International Studies Quarterly 58, no. 1 (2014): 221-224.

${ }^{6}$ Mark Mazower, 'Response', International Studies Quarterly 58, no. 1 (2014): 219-220.

${ }^{7}$ James Rosenau, Turbulence in World Politics: A Theory of Change and Continuity (New Jersey: Princeton University Press, 1990).

${ }^{8}$ See Matthias Hofferberth, 'Mapping the Meanings of Global Governance: A Conceptual Reconstruction of a Floating Signifier', Millennium

${ }^{9}$ Stephen D. Krasner, International Regimes (Ithaca: Cornell University Press, 1983).

${ }^{10}$ Robert Keohane and Joseph S. Nye, Power and Interdependence: World Politics in Transition (Boston: Little, Brown and Company, 1977).
} 
explain change in the wake of new transnational challenges to the Westphalian order. ${ }^{11}$ Consequently, a demand for a 'second generation' of global governance scholarship based on creative theoretical thinking has been driven, in part, by real world events and the pragmatic consequences of first generation rationalist theory frames. As Rosenau foresaw in 1990, world politics display an ever greater potential for turbulence. The practice of global governance is afflicted by a growing array of pathologies, from multilateral gridlocks, to regime fragmentation, and the proliferation of orphan issueareas (migration and climate, to name but two). ${ }^{12}$ For some, a reality of irresolvable interest division has descended, limiting policy options to 'mini-lateralism' and piecemeal efforts towards 'good enough' global governance. ${ }^{13}$ However, for many advocates of a global public goods agenda, this is simply not good enough.

This forum responds to a number of converging developments. Situating contributions broadly within the notion of an interregnum, it is a first cut towards a more innovative global governance research and practice-oriented agenda. The interregnum in global governance points to a state of accelerating transition away from the dominance of sovereignty and the international system, to a potentially more pluralist (and hopefully more democratic) intellectual and practical ecosystem, as well as to new structures of power. As several pieces in this collection underscore, such a transition may in fact take us to new cross-disciplinary terrain that, as we argue below, holds the potential for innovation in IR itself. In an ever more complex global political and structural ecology, the growing governance crisis in gridlocked multilateral forums reflects Gramsci's observation that, 'the old is dying, and the new cannot be born; in this interregnum there arises a great diversity of morbid symptoms'. ${ }^{14}$ If the term 'interregnum' was originally used to denote a time-lag separating the death of one royal sovereign from the enthronement of the successor, this forum adopts a different understanding. Taking its cue from Ken Booth's seminal critique of a 'post-Cold War world', we find that an interregnum 'is a useful way to think about the present'. ${ }^{\text {. }}$

When applied to global governance, this is not an interregnum understood as the absence of conceptual, empirical and theoretical advances. Neither is it a Kuhnian notion of

\footnotetext{
${ }^{11}$ See, for example, Steven Bernstein et al., 'A Tale of Two Copenhagens: Carbon Markets and Climate Governance', Millennium 39, no. 1 (2010): 161-173.

${ }^{12}$ Thomas Hale et al., Gridlock: Why Global Cooperation is Failing When We Need It Most (London: Polity Press, 2013); Ian Goldin, Divided Nations: Why global governance is failing, and what we can do about it (Oxford: Oxford University Press, 2013).

${ }^{13}$ Stewart Patrick, 'The Unruled World: The Case for Good Enough Global Governance', Foreign Affairs, Jan/Feb 2014: 29-48.

${ }^{14}$ Cited in Ken Booth, 'Security and Emancipation', Review of International Studies 17, no. 4 (1991): 315.

${ }^{15}$ Ibid. This idea was revisited by Booth and colleagues at the end of the millennium in Michael Cox et al. (eds.), 'The Interregnum: controversies in world politics, 1989-99', Review of International Studies 25, no. $5,(1999)$.
} 
interregnums between IR paradigms or 'Grand Debates'. ${ }^{16}$ Rather, the idea of the interregnum encourages critical reflection on uncharted 'spaces', where new orders are possible but not yet fully materialised. It is an opportunity to reappraise our analytical and theoretical toolkits with a view to expanding our range of possibilities, not only in terms of explanation, but also in making comprehensible an increasingly complex global governance theatre. Perhaps most importantly, the interregnum also compels us to ground in empirical application a field prone to over-theorisation and eclecticism. This does not preclude a practice-relevant theoretical return to the big questions which should underpin our global political inquiries. That imperative is illustrated in this forum which is eclectic in its empirical analysis, and draws on a variety of disciplines. They are intended to provide a platform for generating new insights and exposing uncharted territories of world politics which may far exceed the confines of conventional IR. The interregnum, we would argue, challenges us to revisit our theoretical priors and to engage a wider community of global governance scholars, policy-makers and practitioners.

\section{Taking stock and charting change}

Change is underway. The optimism of the liberal globalisation debates of the 1990s was underpinned by rationalist interest-driven theoretical frameworks. This is giving way to more searching lines of inquiry from scholars increasingly aware of the limits of pluralist state-based or structuralist views of world politics. They have begun to call for new theories that transcend the (often implicit) methodological nationalism which continues to inform the global governance debate. ${ }^{17}$ Emergent efforts in this direction are apparent as scholars start to probe the outer bounds of new transformational theory and innovative applications to non-traditional governance territory. ${ }^{18}$ While alternative frames, such as polycentric, networked and experimentalist governance are gaining currency within IR circles, there remains little coherence as to the state of the art in global governance theory or practice. ${ }^{19}$ However, the practical and normative appeal of global governance persists, with scholars seizing upon it as a competitor paradigm to anarchy in its ability to organise

\footnotetext{
${ }^{16}$ David Lake, 'Theory is dead, long live theory: The end of the Great Debates and the rise of eclecticism in International Relations', European Journal of International Relations 19, no. 3 (2013): 567-587.

${ }^{17}$ See Philipp Pattberg and Oscar Widerberg, 'The Global Governance of the Environment', Millennium; Thomas Pegram, 'Governing Relationships: The New Architecture in Global Human Rights Governance', Millennium.

${ }^{18}$ See Michele Acuto and Maximilian Mayer, 'The Global Governance of Large Technical Systems', Millennium; Madeline Carr, 'Power Plays in Global Internet Governance, Millennium.

${ }^{19}$ Grainne de Búrca et al., 'New Modes of Pluralist Global Governance', New York University Public Law and Legal Theory Working Papers, Paper 386 (2013): http://lsr.nellco.org/nyu plltwp/386; John Ruggie, 'Global Governance and "New Governance Theory"; Andrew Hurrell, 'The Theory and Practice of Global Governance: The Worst of All Possible Worlds? International Studies Review 13, no. 1 (2011): 144-154.
} 
understandings of world politics. ${ }^{20}$ Yet few would claim it constitutes a theory or an established field of study. Indeed, since Rosenau's seminal contribution, global governance has become a perpetual 'theory in the making'. ${ }^{21}$ Matthias Hofferberth suggests in this forum that global governance has become 'a floating signifier within IR and beyond' ${ }^{22}$

This forum is accordingly representative of, and in dialogue with, an emergent second generation of (cross-disciplinary) global governance research. ${ }^{23} \mathrm{We}$ focus, in particular, on reframing the problematique of global governance from one dominated by multilateral interstate geopolitics, towards a critical reappraisal of both structure and political economy in light of the evident complexity of global governance systems. Similarly, we probe this 'floating signifier' in its expansion beyond IR. Three principal objectives motivate this forum: (1) to contribute to a literature that seeks to clarify the contours of global governance as a field of study, (2) to offer a forum in which scholars from across traditional and non-traditional IR issue-areas can analyse new theoretical and empirical insights related to global governance, and (3) to arrive at some preliminary conclusions about the current state of global governance scholarship, identify points of connection across scholarship, and set a course for further innovation in global governance research.

Our objective is not to elaborate 'a theory of global governance'. Indeed, the totality of global governance cautions against imposing such an ambitious agenda. In contrast to IR, which has been marked (some might say scarred) by paradigm clashes, the complexity of global governance above and below the state demands depth, history and rigour, as opposed to simplistic 'definitive' accounts of cause and effect. This is, after all, in the spirit of an 'interregnum' that, as Ken Booth reiterated again with Michael Cox

\footnotetext{
${ }^{20}$ Michael Barnett and Kathryn Sikkink, 'From International Relations to Global Society', in Christian Reus-Smit and Duncan Snidal (eds.), The Oxford Handbook of International Relations (Oxford: Oxford University Press, 2010): 62-83.

${ }^{21}$ Klaus Dingwerth and Philipp Pattberg, 'Global Governance as a Perspective on World Politics', Global Governance 12, no. 2 (2006): 185-203.

${ }^{22}$ See Hofferberth, 'Mapping the Meanings of Global Governance'

${ }^{23}$ Representative scholarship of this second wave of global governance scholarship includes: Michael Zürn and Benjamin Faude, 'On Fragmentation, Differentiation, and Coordination', Global Environmental Politics 13, no. 3 (2013): 119-130; Jean-Frédéric Morin and Amandine Orsini, 'Insights from Global Environmental Governance', International Studies Review 15, no. 4 (2013): 562-589; Andrew Barry, Material Politics: Disputes along the Pipeline (Oxford: Wiley-Blackwell, 2013); Amy Hinterberg and Natalie Porter, 'Genome and Viral Sovereignty: Tethering the Materials of Global Biomedicine', Public Culture 27, no. 2 (2015, forthcoming); Laura DeNardis and Mark Raymond, 'Thinking Clearly about Multi-stakeholder Internet Governance' (November 14, 2013). Available at SSRN: http://ssrn.com/abstract=2354377; Brian Salter and Charlotte Salter, 'Bioethics and the Global Moral Economy', Science, Technology and Human Values 32, no. 5 (2007), pp. 554-581; Mark B. Salter, 'Tracing the Financial-Security Apparatus', Political Geography (2013): 52-60; Aarti Gupta and Michael Mason (eds.), Transparency in Global Environmental Governance (Boston: MIT Press, 2014) ; Thomas Sikor and Peter Newell, Global Environmental Justice? Geoforum 54 (2014): 151-157; Gregory Shaffer, Transnational Legal Ordering and State Change (Cambridge: Cambridge University Press, 2014)
} 
and Tim Dunne in 1999, 'seemingly defies description' ${ }^{24}$ For Booth and colleagues this is not simply a definitional matter, nor necessarily a call for a new theory of the international, but is also a challenge to the capacity of IR theorists to comprehend a changing reality in its full complexity and possibly ungraspable totality - a condition that well applies to the present state of global governance.

As such, this forum invites direct engagement with some of the assumptions, critiques and claims which animate current thinking on global governance. Articles draw on an array of policy-relevant issue-areas, including the internet (Carr), Large Technical Systems or 'LTS' (Acuto and Mayer), environmental governance (Pattberg and Widerberg) and human rights (Pegram). While not exhaustive, this selection of issues nevertheless exemplifies emergent efforts to cross-fertilise global governance research beyond disciplinary silos and ground the discussion in more systematic conceptual, theoretical and empirical interrogation of global governance. Speaking to this agenda, several themes and issue-areas are explored by the various contributors to the forum. Broadly framed, authors address the contested conceptualisation of global governance (Hofferberth), new modes of multi-level governance (Acuto and Mayer, Carr, Pattberg and Widerberg, and Pegram), application of new analytic frames to non-traditional governance domains (Acuto and Mayer), reclassification of conventional political economy approaches in light of empirical realities (Carr), and the novel empirical extension of conceptual frameworks and their potential to advance debate within and across sub-fields (Pattberg and Widerberg, Pegram).

\section{Setting the Agenda}

As a précis to the forum, we would like to reflect here on three themes which run throughout this collection and expand upon their significance for the study of global governance more generally. All of these themes recur in separate contributions and also benefit greatly from an extended conversation among the authors and colleagues at a workshop convened by University College London (UCL) Institute of Global of Governance in September 2014. ${ }^{25}$ This section is intended to highlight key cross-cutting points of debate among contributors, as well as mark out an agenda for future productive comparative global governance research - with a view to not only making visible "how the world hangs together', but also explaining global governance outcomes across issue areas.

\section{Analytic innovation}

\footnotetext{
${ }^{24}$ Michael Cox et al., 'Introduction: The Interregnum. Controversies in world politics, 1989-99', Review of International Studies 25, no. 5 (1999): 3.

${ }^{25}$ Global Governance and the Theoretical Interregnum, Workshop held at University College London, Institute of Global Governance, London, 23 September 2014.
} 
Global governance remains a highly contested concept, meaning different things to different people. As explored by Hofferberth in his careful conceptual critique of global governance, its ability to shape-shift in terms of both analytical and normative commitments is a constant source of concern for those who wish to give the concept secure ontological roots. However, this conceptual fluidity also opens up new possibilities. Notwithstanding valid disquiet at its status as a 'floating signifier', it has endured as a field of study. As represented in this collection, it provides a potentially productive platform upon which to push beyond disciplinary straitjackets and open up new analytical, theoretical, empirical and discursive vistas for a pluralising global political scholarship. If its heritage can be traced back to the classical regime theory of the 1980s, global governance scholarship - broadly defined - has made significant advances since then in making governance systems legible beyond their component parts, be those a regime, organisation or agent. Advances are particularly evident in terms of descriptive analytics; illuminating what may at first sight appear to be quite inchoate system-level governance domains.

As documented by Pattberg and Widerberg in this forum, perhaps no greater progress has been made in this regard than in the field of global environmental governance. Recognition of a dense web of governance architecture is now sustained by robust empirical observation and underpinned by a large body of theoretical and case-study scholarship. Global environmental scholars have mapped out a variety of geometries of global governance, illustrating the shifting architecture of structures, actors and processes that is shifting towards a governance landscape defined by dyadic relations within metaregime complexes. In turn, the notion of the interregnum would appear to elide not only with this disciplinary turn towards complexity, but also with exogenous forces as scholars and practitioners seek to understand the consequences of geological transformation and the dawning of a new anthropocene age. ${ }^{26}$ The advance in descriptive analytics may therefore be most visible in the environmental field. However, it is now also discernible in other global governance domains, including human rights and the politics of the internet, especially with regard to new modes of governance, as illustrated by other articles in this forum.

Scholarship on growing regime complexity, functional decentralisation to private actors, and the growing prominence of voluntary over binding regulatory frameworks have opened up new modalities of governance to a range of non-traditional actors. They also provide opportunities for inquiry into a diverse range of regulatory logics. In his article,

\footnotetext{
${ }^{26}$ The anthropocene refers to growing scientific evidence which suggests that human activity is fundamentally altering the natural variability of several of Earth's sub-systems with potentially dramatic effect. See Frank Biermann et al., 'Navigating the Anthropocene: Improving Earth System Governance', Science 335 (2012): 1306-1307.
} 
Pegram employs the relatively new theoretical framework of orchestration, as developed by Abbott and colleagues, ${ }^{27}$ to trace out diverse regulatory relations and effects within the issue-specific domain of torture prevention. The article highlights how authority relationships across levels of governance are being reformulated in light of new structural realities and modes of intervention. A focus on orchestration, bypassing and capacitybuilding highlights a shift away from formal rule-making to a more informal power domain of implementation. This reorientation is well underway in the world of practice, and one which global governance scholarship is beginning to comprehend. Although a starkly different issue-area, alternative modes of governance are also apparent in Acuto and Mayer's study of Large Technical Systems as well as in Carr's study of internet governance. All of these contributions raise important questions regarding authority, negotiated sovereignty, accountability and representation. They also draw attention to the informalities of power, and the potential for inequalities to reassert themselves in a world of hierarchies. Particularly pertinent to this exercise in comparative global governance scholarship, these conversations can open up a cross-disciplinary agenda to develop more refined understandings of the new modes of public, private and hybrid governance which are shaping world politics today.

Hybridity, in particular, emerges as an important focus for this second generation of global governance scholarship. As Pegram claims, a pending empirical task involves inquiring into the key political question: how are regulatory arrangements connected to power structures: whose interests are being protected, and whose values promoted? This resonates with the new anthropology of global governance, which seeks to explicitly theorise the practice of global governance. ${ }^{28}$ Hybridity as an analytical lens is used to good effect in the article by Carr in tracing out the connection between technical arrangements and political power structures. Internet governance emerges not so much as a realm of structural coherence, but rather one animated by ideational and material conflict underpinned by powerful political asymmetries.

Importantly, as underlined in other articles (Pattberg and Widerberg as well as Acuto and Mayer), these power dynamics do not necessarily reject traditional alignments of politics. States remain prominent, if not the predominant, power structure in global governance, as evidenced in Carr's evaluation of the role of the US in internet governance. Notwithstanding, the assumption of state-dominance increasingly demands more refined conceptualisation. The articles in this forum, engage different issues such as technology, human rights, or environmental sustainability. Taken together, they offer a powerful reminder that there is fertile comparative terrain to be explored in a new generation of

\footnotetext{
${ }^{27}$ Abbott et al., International Organizations as Orchestrators (Cambridge: Cambridge University Press, 2015 forthcoming).

${ }^{28}$ See Chris Brown, 'The Practice Turn', Phronesis and Classical Realism: Towards a Phronetic International Political Theory', Millennium 40, no. 3 (2012): 439-456.
} 
global governance study. If complexity has emerged as a new problematique for global governance scholarship, much more attention needs to be paid to what hybridity and bricolage actually mean in understanding global governance outcomes. ${ }^{29}$ Carr's examination suggests that the conventional sectoral categorisation of governance actors underspecifies the extent of interpenetration. In turn, the language of multi-stakeholder governance, so prevalent in the 1990s discourse of internet governance, is exposed here as a regulatory mechanism which reinforces rather than equalises power among actors, with the private sector (and disproportionately powerful US corporations) exercising significant authority through technical and infrastructure dominance.

Hybridity also reveals new shades of meaning when applied to Large Technical Systems, as elucidated by Acuto and Mayer. Their contribution decisively moves the analytical frame beyond a preoccupation with rule systems and regulation to also incorporate materiality, mobility, and interconnectedness across multiple scales of governance. This is not, as they argue, a novelty in IR: 'new materialist' currents of IR have indeed begun to take important steps in this direction. ${ }^{30}$ Their contribution is in dialogue with this scholarship, arguing that global governance demands firmer analytical frameworks and clearer objects of geopolitical interest, even when these cut across scales of analysis and issue-areas. They suggest that a focus on Large Technical Systems provides a potentially fruitful middle ground for extending the range of global governance inquiry, while avoiding getting lost in the field's inherent turbulence or local particularisms. They demonstrate the transversal nature of governance systems which are composed of global regulatory frameworks, but which also have a massive quotidian local impact and are deeply embedded in a material reality. In their depiction, as for Carr, internet governance touches on traditional concerns for sovereignty claims, privacy rights and intellectual property, while possessing a latent potential to disrupt and challenge conventional understandings of long-standing IR terrain including sovereignty, war, security and identity.

Tracing out innovation in scholarship offers the promise not only of cross-fertilization across disciplinary silos, but also of making visible change and continuity in the global governance frame. As we seek to make sense of new governance realities across multiple levels, it is important to critically reflect on whether our analytical toolkit is up to the task. In particular, as Hofferberth describes in his article, global governance must be understood in context. Hofferberth contends that its rapid rise to prominence in the lexicon of the 1990s served as both 'a curse and a blessing'. He argues that it has led to a lack of critical reflection resulting in ambiguity, embedding of ideological biases, and

\footnotetext{
${ }^{29}$ See Michele Acuto and Simon Curtis (eds.), Assemblage Thinking and International Relations (London: Palgrave Macmillan, 2014).

${ }^{30}$ For instance, Andrew Barry, Material Politics: Disputes along the Pipeline (Oxford: Wiley-Blackwell, 2013).
} 
conceptual conflation of explanation and description. This poses a challenge to would-be global governance scholars, requiring them to be attentive to the functionalist biases which inform a global governance discourse and analytical frame. It also asserts the importance of historicising analytical innovation in global governance. Where does a global governance system come from? The absence of historical rootedness belies the concept's association with a particular time and place. The language of private or multilevel governance does not exist in a vacuum, but rather responds to a political context and the dynamics of evolving and contested systems.

Viewed in this light, greater institutional memory is required to meet global governance challenges. The impact of transnational migration, the environmental footprint of urban development, and the influence of new private-driven commercial enterprises on the geopolitical distribution of power are long-lived presences that have populated world politics prior to the Westphalian period. This also reasserts the importance not only of structure but also configurations of power and their historical legacy effects. As explored in the article by Carr, it is impossible to understand the current constellation of power structures in internet governance without taking into account the effects of domestic US politics during the 1990s. US government policy under the Clinton and Gore administration directed a significant chunk of the so-called post-Cold War 'peace dividend' into research and development in the science and technology sector. This investment dovetailed with an aggressive economic policy to expand US global markets and a desire to shape the evolution of internet governance was firmly embedded within this agenda. Historical analysis on the impact of these kinds of path dependency and lock-in effects may be the crucial additive to deepening understanding of contemporary constellations of global authority. ${ }^{31}$

\section{Explaining impact}

The second generation of global governance scholarship has made important strides in specifying analytically a pluralising and increasingly complex reality. Less progress has been made in theorising the effects of global governance arrangements. Traditional IR scholarship may be open to criticism for having focused excessively on 'the interstate part of the global governance complex'. ${ }^{32}$ But, as Hofferberth notes, this stands in stark contrast to global governance which still 'fundamentally lacks systematically derived arguments on why change occurs or why a new global order emerges'. ${ }^{33}$ A concern for agency and structures operationalised and interacting at the margins or beyond of the

\footnotetext{
${ }^{31}$ See Craig Murphy, International Organization and Industrial Change: Global Governance since 1850 (Cambridge: Cambridge University Press, 1994); Jennifer Mitzen, The Nineteenth Century Origins of

Global Governance (Chicago: Chicago University Press, 2013)

${ }^{32}$ Weiss and Wilkinson, 'Rethinking Global Governance?': 212.

${ }^{33}$ See Hofferberth, 'Mapping the Meanings of Global Governance'
} 
inter-state domain is an important advance. However, as Pattberg and Widerberg remind us, a necessary corollary is to advance theorising which can explain global governance outcomes. In their article, they highlight four emergent trends in theorising global environmental governance - trends which are also visible across issue-areas tackled in this collection. Pattberg and Widerberg include among these a focus on agency and authority, a more forensic approach to the structural dimension of global governance, related normative questions concerning legitimacy, accountability, equity and fairness, as well as attempts to better integrate governance research into the natural sciences and vice versa.

Of course, a focus on these aspects of global politics is nothing revolutionary. Constructivism placed many of these issues on the agenda in the early $1990 \mathrm{~s} .{ }^{34}$ What is new is a growing body of political economy and empirical scholarship which has sought to assess the impact of these factors on global governance outcomes. All four of these emergent trends display significant diversity of understandings and approaches, suggesting that advancing explanations will entail encouraging theorising of global governance, as opposed to a theory of global governance. This is consistent with a growing consensus around the need for mid-range theory to animate global governance scholarship, as opposed to seeking the grand unifying theories which has driven so much debate in IR. Smith claims that theories 'do not simply explain or predict, they tell us what possibilities exist for human action and intervention; they define not merely our explanatory possibilities, but also our ethical and practical horizons ${ }^{35}$ The articles in this collection employ a pragmatic approach to global governance theory-building, aimed at bridging the gap between abstract theorising and the contextualised world of global governance in practice. If they do not in themselves constitute new theories of global governance, they do spotlight how theorising global governance is currently changing, what the most important challenges are, and what a systematic way forward might look like.

A focus on regime fragmentation (as explored by Pattberg and Widerberg) or orchestration as a new mode of governance (as explored by Pegram) opens up an important comparative agenda conducive to theory-building which centres on how multitudes of agents, institutional structures and material realities interact. They point to a mid-range theoretical concern for scope conditions, inviting reflection on the conditions under which governance interventions are more or less likely to succeed, as well as teasing out the elements required for building explanatory theory. A concern for structural configurations may provide only partial insight into the actual effects of global

\footnotetext{
${ }^{34}$ Alex Wendt, 'Anarchy is what states make of it: the social construction of power politics', International Organization 46, no. 2 (1992): 391-425.

${ }^{35}$ Steve Smith, 'Positivism and beyond', in Steve Smith et al. (eds.), International Theory: Positivism and Beyond (Cambridge: Cambridge University Press, 1996): 113.
} 
governance arrangements, especially once confronted by domestic forces. Nevertheless, highlighting such blindspots can usefully orient future scholarship, not only by deepening inquiry into how institutional design creates and reproduces political power across multiple governance levels, but also in a deeper reflection on the goodness of fit of a global governance frame when seeking to explain local governance effects.

A more fundamental critique of global governance is rooted in the acknowledgement that it is not solely an analytic lens through which to see the world more clearly, it is also a political programme. Viewed through a critical optic, global governance is not simply in the business of managing globalisation, but also legitimating the neoliberal spirit of capitalism and expanding its structures across scales and topical domains. ${ }^{36}$ Certainly, it carries with it a multitude of teleologies, assumptions and (neo)liberal ideological commitments which may serve as a barrier to understanding. The question arises, then, as to whether the fundamental determinants and systemic dynamics driving global power political outcomes are captured in a global governance reading or are actually occurring outside its field of vision. Shifting the central problematique of global governance away from a predominant concern for functionalist rule systems and regulation to system complexity exposes a set of problems inherent to the concept itself. For some observers, global governance gets too much wrong, or misses too much out to be helpful. ${ }^{37}$

The contributions in this forum, while not seeking to vindicate global governance, do seek to productively move the debate beyond a functional focus on efficiency and effectiveness, explicitly drawing attention to normative concerns of power and values. Acuto and Mayer respond to recent calls by global governance scholars to redirect our attention to the big questions which have been marginalised in traditional IR. Carr's contribution is awake to private authority and, in particular, the entwining of global governance and geopolitics, with political conflict transposed to the non-traditional regulatory arena of the internet. This observation raises important issues of spillovers from a failure to accommodate geopolitical conflict into all facets of a globalised world, from the internet, to sustainable resources and disaster risk reduction. In sum, this collection of articles points to new avenues for productive explanatory theorising of global governance. They also highlight pending tasks. In particular, we are now confronted by a pressing need to specify with greater clarity the contemporary power structures of global politics. Agent-centred theorising of global governance is important. However, as posed by Strange almost 20 years ago, the question remains: have we got the structures right? ${ }^{38}$ We need more empirical research to illuminate hybridity in the power

\footnotetext{
${ }^{36}$ Matthew Eagleton-Pierce, 'The concept of governance in the spirit of capitalism', Critical Policy Studies 8, no. 1 (2014): 5-21.

${ }^{37}$ Mark Mazower, 'Response'.

${ }^{38}$ Susan Strange, The Diffusion of Power in the World Economy (Cambridge: Cambridge University Press, 1996).
} 
structures of world politics, drawing on cross-disciplinary resources to expand our theoretical viewpoint and identify what really matters.

\section{Intra, cross and trans-disciplinarity}

Beyond mainstream IR accounts, as our contributors in this special forum remind us, scholars from across disciplines focused on issues as diverse as global security, urbanisation, trade, and international communications have all probed and contested the outer boundaries of methodological nationalism. However, there remains little integrative cross-thematic or cross-disciplinary collaboration explicitly centred on pooling knowledge and advancing debate on global governance theory and practice. Global governance 'thinking' exists at the margins of, and beyond, international scholarship and practice, and is indeed thriving in spaces not conventionally associated with governance. The collection of articles presented here provides substantial evidence of a generic global governance phenomenon which exceeds the bounds of conventional IR, visible from diverse issue-area vantage points and theoretical inclinations. The forum was conceived as an opportunity to bring together some extensions of previous disciplinary frameworks and invite new pathways for exploring global governance realities. This approach shares an affinity with emergent efforts towards productive intra, cross and trans-disciplinary research on global health as pioneered by VU University Amsterdam, Nanyang Technological University (NTU) in Singapore for non-traditional security, and other research centres around the world. ${ }^{39}$

Coupling insights from science and technology studies and the social sciences can open up new, plural and fruitful methodological inquiry. As evidenced by the contributions from Acuto and Mayer, Carr, and Pattberg and Widerberg, a focus on Large Technical Systems, complex assemblages and the agents which populate them can provide a distinctive angle of vision on global governance, raising the question: what are the sociotechnical relays of global governance? As represented by a now vast new materialist IR scholarship, a focus on key components of a science and technology studies agenda can open up technical categories for politicisation. For instance, they can highlight the purposive actors involved in designing technical protocols, how assessments are devised, regulation enforced and evaluative models built into ostensibly technical domains of governance. Such a rationale extends to a variety of other cross-disciplinary engagements. Pattberg and Widerberg further draw attention to both the promise and perils of a tentative engagement of governance research with non-social sciences. They caution against the uncritical usage of science concepts such as resilience, adaptation,

\footnotetext{
${ }^{39}$ See Trans Global Health consortium under the auspices of the Amsterdam Institute for Global Health and Development. Information here: http://www.transglobalhealth.org/\#!/about/partners/ (accessed 3 November 2014). Also Consortium of Non-Traditional Security Studies in Asia based at NTU in Singapore. Information here: http://www.rsis-ntsasia.org/ (accessed 3 November 2014).
} 
complexity and tipping points to describe social realities. However, equally, they express concern at the absence of social science insights from the explanatory modelling widely relied upon by the science and technology community. Cross-disciplinary collaboration requires careful exploration, humility in the wake of disciplinary evolutions, and sustained conversation across ontological and epistemological bases. As Pattberg and Widerberg argue, with few exceptions, the prevalent assumption of politics as a 'black box' is untenable. The conditions under which policies are likely to be effective are important additions to governance modelling which incorporate a concern for implementation. They also signal encouraging moves towards dialogue in the form of Integrated Assessment Models.

Cross-fertilization of global governance research and practice outside disciplinary and scholar-practitioner silos has only just begun. There is much to be gained from further interpenetration across disciplinary lines. Harnessing a fuller knowledge of the interaction effects of global regulatory efforts on actor incentives and value systems may be essential to identifying and overcoming fundamental impediments to progress. The special forum is a modest effort to transcend silos, to incorporate insights from across issue-areas that will advance thinking about modes of governance, and to develop more critical approaches which do not artificially separate technical functions from arrangements of power. Large technical organisations such as the Internet Corporation for Assigned Names and Numbers (ICANN) in internet governance are by no means unique. One can point to a range of standard-setting private agencies across many, if not all, governance domains which exercise authority through novel formulations of structural power. Moving forward, it will be important to identify these new modes of governance empirically, to elaborate tools that can capture their evolution and effects, and to pool knowledge with a view to identifying the important questions which can drive a new and comparative global governance research agenda.

This initial encounter of governance phenomena drawn from across disparate issue-areas demonstrates substantial common ground, overlaps and imperatives to move beyond a silo approach towards better understanding and theorising of global governance. All contributors here share in common a concern for how governance issues which do not conform to established political boundaries require some form of management articulated and operationalised at multiple scales of authority. If the objective of this initiative is not to arrive at a grand agreement on what global governance actually is, we do believe that theorising global governance in light of cross-disciplinary insights holds significant promise for further productive dialogue across disciplines on the major global governance questions of our age. 